\title{
The development of the well-being of students of the risk group as an indicator of improving the quality of higher education in the context of the Bologna process
}

\author{
Svetlana Khusainova*, Ekaterina Palekha \\ Institute of Pedagogy, Psychology and Social Problems, Isaeva st., 12, 420039 Kazan, Russia
}

\begin{abstract}
The relevance of the article is due to the need to develop the well-being of students included in a special risk group because of their deviancy: that affects the level of the quality indicator of higher education. This problem is presented in the aspect of development of lifelong learning in the context of the Bologna process. The purpose of the article is to identify the well-being of students of the risk group as an indicator of improving the quality of higher education correlated with personalityoriented learning and the idea of increase of their mobility and competitiveness in the labor market. The authors reveal that students of the risk group with a low level of well-being and a low level of self-acceptance face difficulties in setting an adequate goal in life, as well as in establishing the necessary contacts that contribute to the creation of autonomy that determines the satisfaction of the proposed conditions of their development. The authors show the essence of the quality indicator of higher education, which consists in resilience, involvement in one's own activities and risk taking, which is realized through the active assimilation of knowledge from experience and its usage. It is proposed to consider the development of students' well-being as an additional indicator of the quality of higher education. It has been proven that the high value of the diversity of education systems is recognized as one of the missions of higher education to develop the well-being of students of the risk group. The article could be interesting for educational psychologists, graduate students and researchers of risk groups in the education system.
\end{abstract}

\section{Introduction}

The challenges of the new era are aimed at changing and improving the multifaceted aspects of higher education. Responding to these changes requires continuous quality control. The diversity of higher education is constantly supported by public policies and the need to enhance the relevance of its missions of teaching, research and socio-cultural

${ }^{*}$ Corresponding author: $\underline{\text { sv husainova@mail.ru }}$ 
development. Students, institutions and other participants of higher education relations must be adequately prepared for situations of change in a rapidly changing world.

One of such components of quality control can be the criteria of one's satisfaction with life and with oneself, which also denotes a high level of psychological well-being while achieving the goal. The influence of this phenomenon on a human life and activities in various areas contributes to an increase in the level of subjective well-being.

Researchers of the problems of psychological well-being noted that this area is becoming more and more relevant. E. Diener, K. Petersen, K. Sheldon, R. Ryan, S. Lubomirski, C. Ryff, D. Kahneman and others support the necessity of study of psychological well-being in their research $[1,2,3,4,5,6]$.

Russian researchers N. K. Bakhareva, M. V. Buchatskaya have also studied the concept of psychological well-being of the subjective and psychological well-being of the individual. The study of resilience as a special system of beliefs about oneself, the world and relations to the world is the topic of the famous works of D. A. Leontiev [7]. The applied aspect of the phenomenon is expressed in the personality variable term which provides mental health and opposition to situations of change.

Speaking about the circumstances of a person's life, it is always assumed that the manifestation of events is shifted from a positive to a negative one or the occurrence of a situation of change in the process of activities carrying out. Such circumstances carry the perceived risks and cause in a person certain reactions to negative events. Not everyone succeeds, but the subject can immediately cope with the challenges of society, the development of technologies, economic changes that entail negative experiences. In fact, undesirable factors create risk that can occur in a particular situation or be taken into account and minimized. In situations of change, the behavior of persons at risk is noted with the inability to cope with difficulties (loss of normal conditions for development, loss of life / health, etc.). This category was defined by researchers as a "risk group". This category is described by L. Ya. Oliferenko, T. I. Shulga, I. F. Dementieva as persons, due to the circumstances of life, most susceptible to negative external influences, both from society and its criminal elements, contributing to the emergence of maladjustment [8].

Previously S. V. Khusainova and her colleagues [9, 10, 11, 12] described some features of the risk group in order to create a number of psychological and pedagogical recommendations to the Russian educational zone, the implementation of them is supposed to contribute to the prevention of the manifestation of deviant behavior of student youth.

M. Seligman considers psychological well-being through the prism of prosperity, which determines the state of stable balance expressed in a high level of psychological, social and emotional well-being. He bases it on the category of "passion" and shows in his research that students' enthusiasm is mainly manifested outside the educational organization with a high degree of cognitive motivation. Students perceive the educational organization in the range from apathy to irritation. This was confirmed by the researcher in cross-cultural studies $[13,14]$.

The study of the quality of life and mental health was first carried out by D. Gurin, D. Verov, Sh. Feld. Further, these studies gained their significance in the study of the balance of positive and negative emotions as the main indicators of psychological wellbeing of a person by N. Bradburn and D. Kaplovich $[15,16]$. Later A. Campbell, P. E. Converse, W. L. Rodgers conducted a study of life satisfaction, without relying on the concept of happiness. As a result, two paradigms for the study of psychological well-being were derived [17].

I. V. Dubrovina [18] emphasizes that one of the priority tasks is the development of a psychological service, the work of which is aimed at solving social problems of overcoming negative emotions and states. Psychological support, in her opinion, should be 
directed to the development of positive emotions and states aimed at experiencing wellbeing.

Learning about the world needs to pass through the prism of spiritual values that pay attention to respect for people and themselves as a person. This will provide an answer to some of life's questions: What is the feeling of happiness? Is satisfaction an indicator of psychological well-being? How can you solve problems successfully and experience positive thoughts during this time?

Attention concentration on positive experiences contributes to the emergence of "student's enthusiasm", correlates with the feeling of pleasure from the task being performed and awakening interest in learning activities. The basis of the study consciousness is attention concentration, and interest contributes to its maintenance, stimulating activity and the desire to continue it.

Universities students who are in classrooms for a long time consider classes unattractive. Classes, conducted in an active form, contribute to an increase in concentration in educational activities and increase the level of enthusiasm, where the task begins to be perceived as feasible.

Psychological well-being acts as a predictive parameter for understanding one's own abilities aimed at solving educational problems. Passion for activities that bring them closer to the realization of the goal raises the expectation of success, but if the activity consists only of simple tasks, satisfaction is impossible. A level of difficulty is needed that promotes the acquisition of problem-solving skills that improve the quality of education.

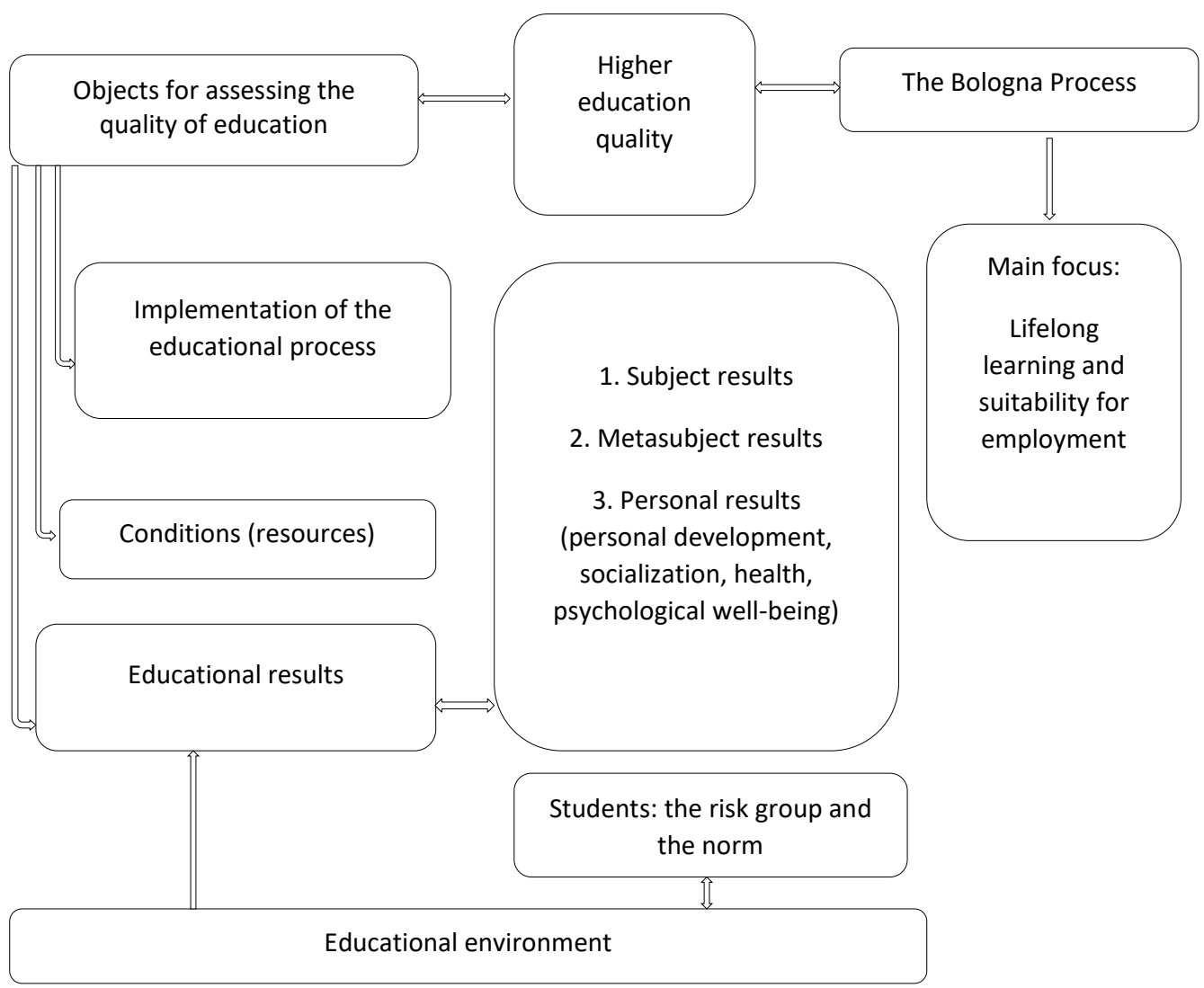

Fig. 1. Psychological well-being as an indicator of improving the quality of higher education in the context of the Bologna process. 
Figure 1 shows that psychological well-being can be considered as an indicator of improving the quality of higher education in the context of the Bologna process: to a greater extent, it will influence personal results, as well as have a direct impact on educational results. This means that both the environment and the conditions of learning, and the peculiarities of the implementation of the educational process invariably affect such a factor as the well-being of the student's personality.

M. A. Artamonova in her research has shown that "the social aspect of the Bologna Process emphasizes the social characteristics of higher education aimed at providing equal opportunities for quality education. Access to higher education should be enhanced by strengthening the capacity of students from underrepresented groups and providing the right conditions for completing their studies. This involves improving the learning environment, removing all barriers to learning, and creating the right economic environment for students to benefit from learning opportunities at all levels. Each participating country will set measurable goals for increased overall participation and increased participation of underrepresented groups in higher education, to be achieved by the end of the next decade. Efforts to achieve objectivity in higher education must be complemented by actions in other parts of the education system" [19].

\section{Methods}

Theoretical methods were used to obtain generalized knowledge about any psychological phenomenon.

The study used the following methods. Methodology for assessing psychological wellbeing (C. Ryff) was designed to measure the severity of the main components of psychological well-being. Within the framework of the eudemonistic approach, based on the earlier research of M. Yagoda, C. Ryff developed a multidimensional model of psychological well-being. It includes six main components of psychological well-being: having a purpose in life, positive relationships with others, personal growth, environmental management, self-acceptance and autonomy. This technique was adapted into Russian by T. D. Shevelenkova and T. P. Fesenko in 2005 [20].

The Resilience Questionnaire by S. Muddy, adapted by D. A. Leontiev, to identify readiness for self-development. The vitality test is an adaptation of D. A. Leontiev. The Hardiness Survey was developed by the American psychologist Salvatore Maddy. Resilience is a system of beliefs about oneself, the world, and relationships with it, which enable a person to withstand and effectively overcome stressful situations [7].

The study involved first and second year students of Kazan Federal University - these are 65 people: 29 boys and 36 girls aged 18 to 20 years.

\section{Analysis and results}

The purpose of the article is to identify the well-being of students of the risk group as an indicator of the quality of higher education in correlation with student-centered learning. This contributes to the success and satisfaction of the anticipated developmental conditions affecting the level of well-being of students of the risk group, increasing their mobility and competitiveness in the labor market.

For the study, the students were divided into subgroups according to indicators of psychological well-being. The risk group and the group of students corresponding to the social norm were determined. 


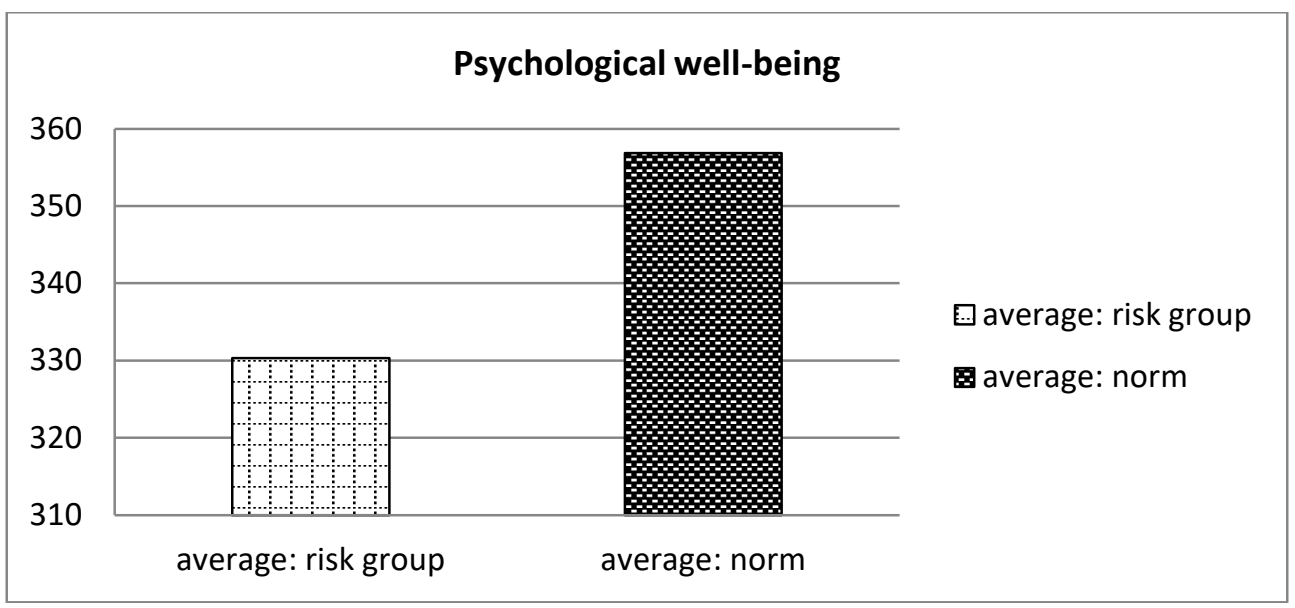

Fig. 2. Indicators of well-being of students of the risk group and the group of students corresponding to the social norm.

The figure 2 shows that students of the risk group have a low level of meaningfulness of life, value-semantic competence and motivation.

Interpretation of students' answers according to the methodology scales indicate that they are dissatisfied with themselves, disappointed with the events of their past, negatively assess some of their personal qualities and would like to be not who they are.

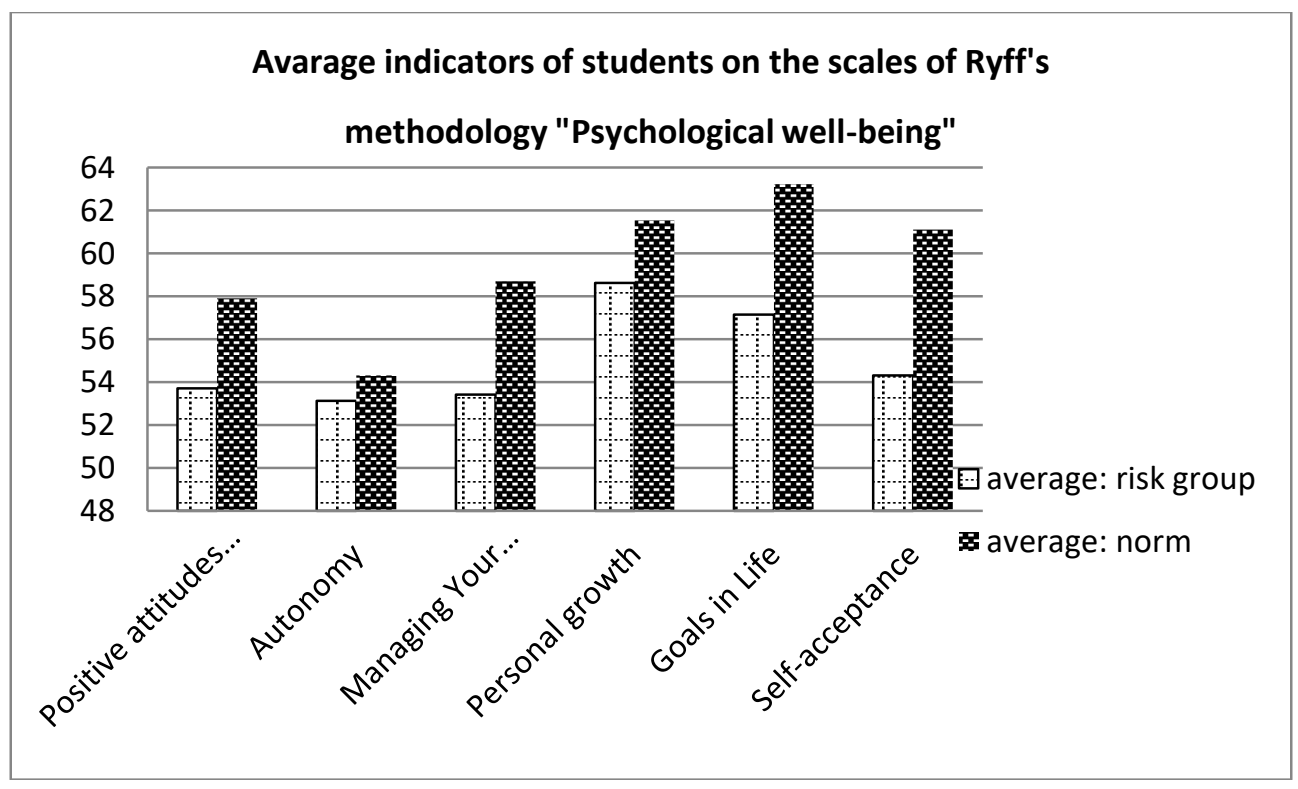

Fig. 3. Indicators of the scales of well-being of students of the risk group and the group of students corresponding to the social norm.

Figure 3 shows that the students of the risk group have indicators on all scales lower than those of students of the social norm. This suggests that they have no satisfaction of aspirations, which indicates the specificity of the conditions in which the learning process takes place. It is currently a distance learning form. There are some limitations for the realization of goals when solving educational problems. 


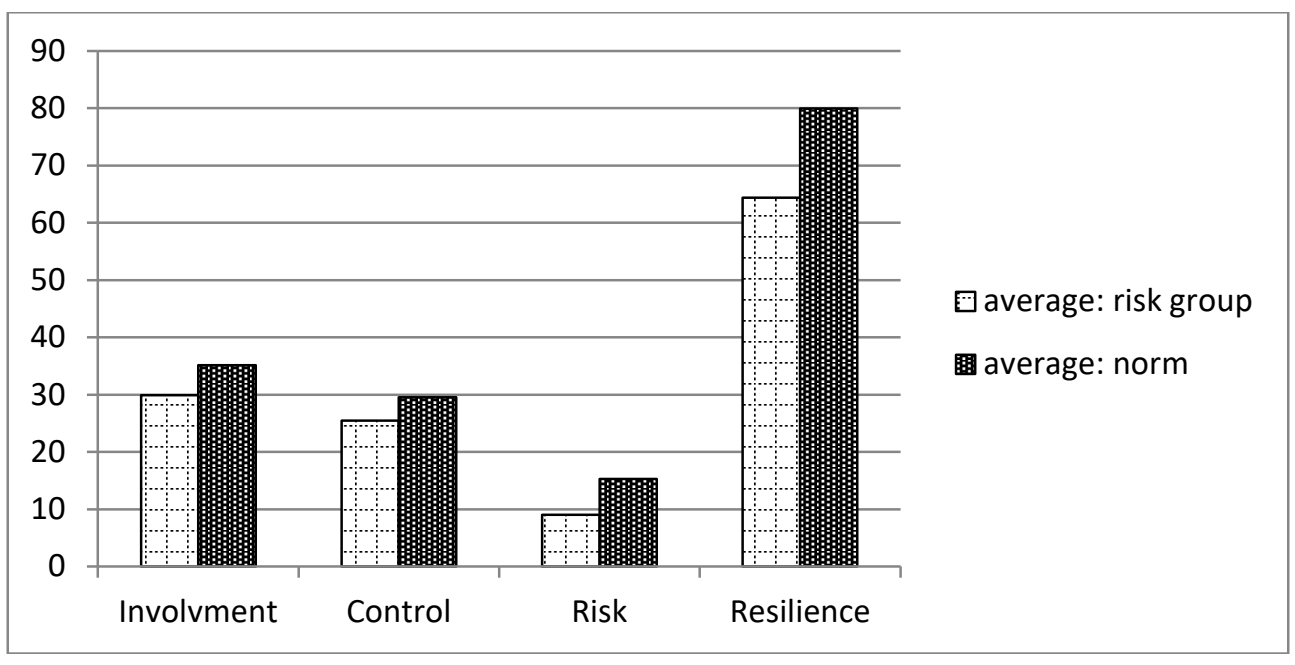

Fig. 4. Indicators of resilience of students of the risk group and the group of students corresponding to the social norm.

The results of students obtained according to the "Resilience" methodology revealed (Fig. 4) that the average values on the scales "Engagement", "Control", "Risk", "Resilience" among students of the risk group are lower than those of ordinary students (norm), which speaks of an insufficiently formed system beliefs that enable the learner to perceive and deal with a difficult situation.

To identify the necessary indicator that contributes to improving the quality of higher education, correlated with maintaining the satisfaction of the proposed development conditions, a one-way analysis of variance was made.

Table 1. The matrix of coefficients of assessments of well-being and resilience components.

\begin{tabular}{|l|r|r|}
\hline \multirow{2}{*}{} & \multicolumn{2}{|c|}{ Component } \\
\cline { 2 - 3 } & \multicolumn{1}{|c|}{1} & \multicolumn{1}{c|}{2} \\
\hline Positive attitude towards others &, 836 &,- 094 \\
\hline Autonomy &, 969 &,- 500 \\
\hline Environmental management &, 722 &,- 050 \\
\hline Personal growth &, 351 &,- 432 \\
\hline Life goals &, 715 &,- 530 \\
\hline Self-acceptance &, 802 &, 010 \\
\hline Psychological well-being &, 935 &,- 090 \\
\hline Involvement &, 054 &, 553 \\
\hline Control &, 050 &, 665 \\
\hline Risk &,- 231 &, 839 \\
\hline Resilience &, 031 &, 918 \\
\hline
\end{tabular}

Isolation method: Principal component analysis. Rotation method: Varimax with Kaiser normalization.

The obtained results of the variance analysis showed that two factors (load $67 \%$ and 74 $\%)$ were identified that determine 1 - a positive attitude towards life and 2 - resilience in a situation of change. The first characterizes a positive attitude, harmony with the outside world and the experience of happiness. The second factor characterizes resilience in relation to current events. These results confirm that psychological well-being can act as indicators of improving the quality of higher education as objects of assessing the quality of education in educational institutions. The main parameters for assessing quality will be 
educational results: subject results, metasubject results, personal results (personal development, socialization, health, psychological well-being). Psychological well-being is an indicator of improving the quality of higher education that contributes to the satisfaction of the proposed development conditions.

\section{Conclusions}

1. The need to develop the well-being of students of the risk group, which affects the level of expression of the indicator of the higher education quality, has been revealed. This problem was presented in the aspect of the development of "lifelong learning" in the Bologna process context.

2. It has been determined that the well-being of students of the risk group as an indicator of the quality of higher education is correlated with personality-oriented learning. This way of learning contributes to the success and satisfaction of the expected developmental conditions, and also affects the level of well-being of students of the risk group in order to increase their mobility and competitiveness in the labor market.

3. It has been proven that students of the risk group with a low level of well-being and a low level of self-acceptance face difficulties in setting an adequate goal in life, as well as in establishing the necessary contacts that contribute to the creation of autonomy that determines the satisfaction of the proposed development conditions.

4. The essence of the quality indicator of higher education has been revealed, it consists in resilience, involvement in one's own activities and risk taking, which is realized through the active assimilation of knowledge from experience and its subsequent use.

5. It is proposed to consider the development of students' well-being as an additional indicator of the quality of higher education. It has been proven that the high value of the diversity of education systems is recognized as one of the missions of higher education to develop the well-being of students of the risk group.

\section{Acknowledgements}

The article has been prepared as a part of the public task of the Institute of Pedagogy, Psychology and Social Problems on the topic No. FNRR-2021-0003.

\section{References}

1. E. Diener, C. Diener, Most people are happy, Psychological Science, no. 7, 181 (1996)

2. C. Peterson, M. Seligman, Character strengths and virtues: A handbook and classification (2004).

3. C. D. Ryff, C. L. Keyes, The Structure of Psychological Well-Being Revisited, Journal of Personality and Social Psychology, vol. 69, 719 (1995)

4. C. D. Ryff, Psychological well-being, Encyclopedia of gerontology: age, aging, and the aged (1996)

5. C. D. Ryff, C. Keyes, The Structure of Psychological Well-Being Revisited, Journal of Personality and Social Psychology, vol. 69, no. 4, 719 (1995)

6. C. D. Ryff, Psychological well-being, 269 (2014)

7. D. A. Leontiev, E. I. Rasskazova, Vitality test, 63 (2006)

8. L. Ya. Oliferenko, T. I. Shulga, I. F. Dementyeva, Socio-pedagogical support of children at risk: textbook (2004)

9. S. V. Khusainova, E. S. Palekha, R. O. Galieva, R. N. Khakimzyanov, Deviancy VS extremism: terms, prerequisites, research (2019) 
10. S. V. Khusainova S., E. Palekha, Generetion Z: ways, methods and forms of training (the questionofincreasing the motivation of students and the professional growth of teachers), Proceedings 12th International Conference of Education, Research and Innovation, 3670 (2019)

11. S. V. Khusainova, External influence as a factor in the safety of the educational environment. Scientific opinion, 1, 85 (2018)

12. S. V. Khusainova, R. N. Khakimzyanov, Study of psychological features of the personality prone to deviant behavior, Kazan pedagogical journal, 6(137), 195 (2019)

13. M. Seligman, Flourish: A Visionary New Understanding of Happiness and Well-being (2012)

14. M. Seligman, The Optimistic Child (2007)

15. N. M. Bradburn, The Structure of Psychological Well-Being (1969)

16. N. M. Bradburn, D. Caplovitz, Reports on Happiness: A Pilot Study of Behavior Related to Mental Health (1965)

17. A. Campbell, P. E. Converse, W. L. Rodgers, The Quality of American Life (1975)

18. I. V. Dubrovina, Psychological well-being of schoolchildren in the system of modern education: textbook (2016)

19. M. A. Artamonova, Higher education reforms and the Bologna process in Russia (a private view of a methodologist), 279 (2008)

20. T. D. Shevelenkova, T. P. Fesenko, Psychological well-being of the individual, Psychological Diagnostics, no. 3 (2005) 